\title{
BMJ Open Are higher blood mercury levels associated with dry eye symptoms in adult Koreans? A population-based cross-sectional study
}

\author{
So-Hyang Chung, ${ }^{1}$ Jun-Pyo Myong ${ }^{2}$
}

To cite: Chung S-H, Myong J-P. Are higher blood mercury levels associated with dry eye symptoms in adult Koreans? A population-based crosssectional study. BMJ Open 2016;6:e010985.

doi:10.1136/bmjopen-2015010985

- Prepublication history for this paper is available online. To view these files please visit the journal online (http://dx.doi.org/10.1136/ bmjopen-2015-010985).

Received 26 December 2015 Revised 15 March 2016 Accepted 24 March 2016

CrossMark

\footnotetext{
${ }^{1}$ Department of Ophthalmology and Visual Science, Seoul St. Mary's Hospital, and Catholic Institute for Visual Science, College of Medicine, The Catholic University of Korea, Seoul, Republic of Korea

${ }^{2}$ Department of Occupational and Environmental Medicine, Center for Occupational and Environmental Medicine, Seoul St. Mary's Hospital, College of Medicine, The Catholic University of Korea, Seoul, Republic of Korea
}

Correspondence to Professor Jun-Pyo Myong; dr_mjp@naver.com

\section{ABSTRACT}

Objectives: The purpose of this study was to investigate whether blood mercury concentrations associated with the presence of dry eye symptoms in a nationally representative Korean population.

Methods: Population-based prospective crosssectional study using the heavy metal data set of the 2010-2012 Korean National Health and Nutrition Examination Survey (KNHANES). A total of 4761 adult Koreans were the eligible population in this study. Of the 7162 survey participants, 2401 were excluded because they were $<19$ years of age, there were missing data in the heavy metal data set, or they had diabetes, rheumatoid arthritis, thyroid disease, asthma, depression and/or under-the-eye surgery. Blood mercury levels were measured on the day the participants completed a questionnaire regarding the presence of dry eye symptoms (persistent dryness or eye irritation). The population was divided into low and high groups by median level $(4.26$ and $2.89 \mu \mathrm{g} / \mathrm{L}$ for males and females, respectively).

Results: Self-reported dry eye symptoms were present in $13.0 \%$ of the cohort. Participants with dry eye symptoms were significantly more likely to have blood mercury levels exceeding the median than those without dry eye symptoms ( $45.7 \%$ vs $51.7 \%$, $\mathrm{p}=0.021$ ). Logistic regression analysis showed that, after adjusting for age, gender, education, total household income, smoking status, heavy alcohol use, sleep time, perceived stress status, total cholesterol levels and atopy history, dry eye symptoms were significantly associated with blood mercury levels that exceeded the median (reference: lower mercury group; OR, 1.324; 95\% Cl 1.059 to 1.655; $p<0.05$ ).

Conclusions: High blood mercury levels were associated with dry eye symptoms in a nationally representative Korean population.

\section{INTRODUCTION}

Dry eye syndrome is the most common disease for which patients visit ophthalmologists. Large epidemiological studies show that the prevalence of dry eye at various ages

\section{Strengths and limitations of this study}

- This study identified the blood mercury levels and dry eye symptoms of a nationally representative population in South Korea.

- The study population was large and the weights were considered.

- Potential confounders were excluded.

- The cross-sectional design of the study means that this association cannot be interpreted as a cause-effect relationship.

ranges from $5 \%^{1}$ to $>35 \% .^{2}$ It is currently regarded as tear film instability and ocular surface inflammation with ocular surface damage. ${ }^{1}$ Dry eye symptoms include dryness, sensation of foreign body or burning, photophobia, pain and visual symptoms. These symptoms affect daily living activities, including important tasks such as driving. ${ }^{2}$ Dry eye syndrome is most commonly diagnosed using symptom questionnaires because they yield reliable diagnoses. ${ }^{3}$

An international dry eye workshop reported that the mostly consistent risk factors of dry eye syndrome included older age, female gender, postmenopausal oestrogen therapy, ocular surface surgery history, antihistamine medications, connective tissue disease, radiation therapy, haematopoietic stem cell transplantation, vitamin A deficiency, hepatitis $\mathrm{C}$ infection and androgen deficiency. ${ }^{4}$

Mercury is a ubiquitous metal in the environment that adversely affects health after absorption. Organic/inorganic/metal mercury can enter the body through various routes, including the gastrointestinal tract, skin and respiratory tract. After entry, it accumulates from the blood in the brain, kidney, liver, hair, eye and skin. ${ }^{5}$ Ionic mercury in the blood is transported to the retina pigment epithelium, where it accumulates in 
photoreceptors, the plexiform layer and ganglion cells, and is also found in the vitreous in animal studies. ${ }^{6-8} \mathrm{In}$ human studies, chronic exposure to methylmercury can affect eye movement. ${ }^{9}$ With regard to the conjunctiva, one previous report demonstrated in rabbits that metallic mercury in the conjunctiva increased lymphocytes and macrophages and was also associated with increased amounts of altered mucus. ${ }^{10}$ Since inflammation has a prominent role in the development and amplification of the signs and symptoms of dry eye syndrome, ${ }^{11}$ we hypothesised that altered mucus and conjunctiva inflammation by exposure to mercury might affect dry eye syndrome.

However, there are few studies that have investigated the association between dry eye and blood mercury level. This question was addressed by performing this prospective cross-sectional study of a general nationwide population in South Korea that is exposed to low levels of environmental mercury.

\section{METHODS}

\section{Study design}

The study design of the present study is a populationbased prospective cross-sectional study using the heavy metal data set of the 2010-2012 Korean National Health and Nutrition Examination Survey.

\section{Study population}

Since 1998, the Korea Center for Disease Control and Prevention (KCDC) has conducted the Korean National Health and Nutrition Examination Survey (KNHANES) to assess the health and nutritional status of South Koreans. The survey employs a rolling sampling design to select representative population samples of non-institutionalised civilians. The fifth survey (KNHANES V) was performed between 2010 and 2012. Details concerning the sampling frames of participants are described elsewhere. ${ }^{12}{ }^{13}$ The heavy metal data set in KNHANES $\mathrm{V}$ was the source of the raw data in this study. Participants were excluded if their age was $<19$ years, data in the heavy metal data set were missing, they had diagnosed diabetes, rheumatoid arthritis, asthma, depression, thyroid disease, or they had a history of eye surgery. Written informed consent was obtained from all KNHANES participants by KCDC. Moreover, KCDC has released the data, which are anonymised. All data are publicly available.

\section{Measurement of blood mercury concentrations}

Blood mercury analysis was performed by the Neodin Medical Institute in Seoul; this laboratory has been certified by KCDC and the Ministry of Labor for the measurement of heavy metals. As part of the health examinations of each KNHANES participant, an experienced medical technician drew $3 \mathrm{~mL}$ of whole blood into an EDTA tube for trace element measurement. The mercury levels in the whole blood were measured using gold amalgam sampling methods with a Mercury analyser (DMA-80; Milestone, Bergamo, Italy). For external quality assurance, we followed several protocols, namely, those of the German External Quality Assessment Scheme (G-EQUAS; Friedrick Alexander University), US Centers for Disease Control and Prevention, and Korean National Institute of Environmental Research. Monthly internal quality assurance and control programmes were performed with three different reference materials (Bio-rad, G-EQUAS 7B, and G-EQUAS 1A). The coefficients of variation were $0.78-3.22 \%, 1.54-6.08 \%$ and 0.84-3.52\% for Bio-rad, G-EQUAS 7B and G-EQUAS 1A, respectively. The lower limit of detection for mercury in the blood was $0.05 \mu \mathrm{L}$.

\section{Definition of dry eye symptoms}

Since July 2008, the South Korean Ophthalmological Society has participated in KNHANES by performing ophthalmological interviews and examinations of the study participants. Participants were deemed to have dry eye symptoms if they responded positively to the questionnaire item that asked if the person had dry eye symptoms, namely, persistent dryness or sense of eye irritation. If the participant said that they only had these symptoms 'sometimes' or 'occasionally', they were deemed not to have dry eye.

\section{Other variables}

Education status was divided into four groups: $\leq 6,7-9$, 10-12 and $\geq 13$ years of schooling. Total household income was divided into quartiles $(\mathrm{Q})$, where $\mathrm{Q} 1$ and Q4 reflect the lowest and highest incomes of the population, respectively. Smoking status was categorised as nonsmoking, ex-smoker or current smoker. Heavy alcohol use was defined as consuming seven or more drinks (men) or five or more (women) on a single occasion on five or more days in a month. Sleeping time was categorised as sleeping $<6 \mathrm{~h}$ or $\geq 6 \mathrm{~h}$. Perceived stress and those diagnosed with atopic disease were classified as 'yes/no'. Cholesterol level was determined during fasting and categorised as $<240$ and $\geq 240 \mathrm{mg} / \mathrm{dL}$. Anaemia was defined as follows: for males with a haemoglobin level $<13 \mathrm{~g} / \mathrm{dL}$, pregnant females with a haemoglobin level $<11 \mathrm{~g} / \mathrm{dL}$, and non-pregnant females with a haemoglobin level $<12 \mathrm{~g} / \mathrm{dL}$.

\section{Statistical analysis}

Since KNHANES is a stratified multistage clustered probability design, the sampling weights, strata and clusters were included in all survey analyses. Mercury in the blood was expressed as geometric mean with geometric SE. Participants were deemed to have high blood mercury levels if their levels exceeded the median level of the cohort, which was 4.26 and $2.89 \mu \mathrm{g} / \mathrm{L}$ for men and women, respectively. To determine whether dry eye symptoms associated with the categorical variables described above, Rao-Scott $\chi^{2}$ analysis was performed. To determine whether dry eye symptoms were associated 
with continuous variables, survey regression analysis was performed in accordance with KNHANES statistical guidelines. ${ }^{13}$ To evaluate the association between dry eye symptoms and blood mercury level, survey multiple logistic regression analysis was applied after adjustment for age, gender, education, household income, smoking status, heavy alcohol drinking, sleep time, perceived stress status, blood cholesterol levels and atopy history (SAS Syntax: PROC SURVEYREG). To determine the potential bias, the sensitivity test was done with the optimal cut-off level is the median $\pm 10 \%$ (ie, between the 45th (3.99 and $2.72 \mu \mathrm{g} / \mathrm{L}$ for males and females, respectively) and 55th (4.26 and $2.89 \mu \mathrm{g} / \mathrm{L}$ for males and females, respectively) centiles) as the ORs and $p$ values for the relationship between dry eye symptoms and these alternative cut-offs. All statistical analyses were performed using SAS V.9.4 (Statistical Analysis Software Institute, Cary, North Carolina, USA).

\section{RESULTS}

KNHANES V was performed in 2010-2012. In 2010, 2011 and 2012, 8958, 8518 and 8058 participants were surveyed, respectively. The KNHANES $\mathrm{V}$ heavy metal data set consisted of the 7162 participants whose blood concentrations of heavy metals were determined. Of these 7162 participants, 2355, 2395 and 2412 were surveyed in 2010, 2011 and 2012, respectively. A total of 2401 participants were excluded because their age was $<19$ years $(\mathrm{n}=1112)$, there were missing data in the heavy metal data set $(n=18)$, they had been diagnosed with diabetes $(\mathrm{n}=134)$, rheumatic arthritis $(\mathrm{n}=90)$, asthma $(n=110)$, depression $(n=171)$, thyroid disease $(n=152)$, or they had a history of eye surgery $(n=614)$. The remaining 4761 participants were included in this study.

The general characteristics, socioeconomic status and blood mercury levels of the study participants are shown in table 1 . The mean age of the study population was $39.6 \pm 0.2$ years. Men were disproportionately represented $(59.7 \%)$. More than $30 \%$ were current smokers and $21 \%$ were heavy alcohol users. Thirteen per cent of participants reported having persistent dry eye symptoms.

Men with and without dry eye had median blood mercury levels of 4.530 and $4.250 \mu \mathrm{g} / \mathrm{L}$, respectively. In women, these values were 2.985 and $2.867 \mu \mathrm{g} / \mathrm{L}$, respectively.

Table 2 compares the participants with and without dry eye symptoms in terms of various demographic and clinical variables. Women, non-smokers, non-heavy alcohol drinkers, participants who perceived that they were stressed, and participants with higher levels of blood mercury (defined as $\geq$ median levels of the study population) were more likely to have dry eye symptoms than the comparators (all $\mathrm{p}<0.05)$.

Table 3 shows the ORs and 95\% CIs for the association between the presence of dry eye symptoms and the demographic and clinical variables. Simple survey logistic regression analyses showed that the presence of dry eye symptoms was associated with an age of 70 years or older, female gender, less education, not smoking, not being a heavy alcohol drinker, perceiving oneself to be stressed, and higher levels (ie, $\geq$ median values) of blood mercury (all $\mathrm{p}<0.05)$. In multiple survey logistic regression analysis, after adjusting for age, gender, education, total household income, smoking status, heavy alcohol use, sleep time, perceived stress, total cholesterol levels and atopy history, higher blood mercury levels $(\geq$ median value) were significantly associated with the presence of dry eye symptoms (reference: <median value; OR, 1.324; 95\% CI 1.059 to $1.655 ; \mathrm{p}<0.05$ ) (table 3 ).

Moreover, when the multivariate survey logistic regression analysis on the whole cohort was repeated using the median-10\% range $(3.99$ and $2.72 \mu \mathrm{g} / \mathrm{L}$ for men and women, respectively) or median $+10 \%$ range (4.61 and $3.10 \mu \mathrm{g} / \mathrm{L}$ for men and women, respectively) values as the cut-off to discriminate between lower and higher blood mercury levels, similar associations between the presence of dry eye symptoms and higher blood mercury levels were observed as when the median values were used (table 4).

\section{DISCUSSION}

To the best of our knowledge, this study on a large population-based nationally representative cohort in South Korea is the first study to investigate the association between dry eye syndrome and blood mercury levels. Our results show an association between dry eye symptoms and blood mercury levels after adjusting for the relevant risk factors.

Mercury is a toxic metallic element that can have a significant impact on human health, even when the exposure is relatively small. ${ }^{14}$ Mercury pollution led to public health disasters in Minamata, Japan and in Iraq. ${ }^{5} 1516$ Although high levels of mercury exposure in the world have decreased, environmental exposure to mercury continues through seafood consumption, waste incineration, energy production and use of dental amalgams. ${ }^{17} 18$ In Korea, the main source of mercury is likely to be the frequent consumption of fish, including shellfish: the epidemiological studies of Kim and Lee showed that, in Korea, people with a higher intake of fish and shellfish also have higher blood mercury levels. ${ }^{19} \quad 20$ Notably, a recent study on the health effects of mercury in American adults showed that the participants had a median blood mercury level of about $1.0 \mu \mathrm{g} / \mathrm{L}$, which is much lower than that in the Korean population. ${ }^{21}$ Since Koreans differ from Americans in their dietary habits, this observation suggests that the high blood mercury levels of Koreans reflects their diet.

Several hypothetical mechanisms may explain the association we observed between high blood mercury levels and dry eye symptoms. The first is that blood mercury accumulates in the eye and may alter the conjunctival mucus and induce conjunctival inflammation. ${ }^{5}$ The gel-like tear layer over the ocular surface is composed of 
Table 1 General characteristics, socioeconomic status and blood mercury levels of the study cohort

\begin{tabular}{|c|c|c|c|c|c|}
\hline Variables & No. & Weighted No. & Weighted mean & Weighted \% & $\overline{\mathrm{SE}}$ \\
\hline Age (years) & & & 39.6 & & 0.2 \\
\hline$<30$ & 1015 & 3844732 & & 30.6 & 0.8 \\
\hline $30-39$ & 999 & 2717085 & & 21.6 & 0.6 \\
\hline $40-49$ & 1018 & 2899013 & & 23.0 & 0.5 \\
\hline $50-59$ & 938 & 2060342 & & 16.4 & 0.5 \\
\hline $60-69$ & 696 & 951896 & & 7.6 & 0.3 \\
\hline$\geq 70$ & 96 & 110698 & & 0.9 & 0.1 \\
\hline \multicolumn{6}{|l|}{ Gender } \\
\hline Men & 2498 & 7512566 & & 59.7 & 0.6 \\
\hline Women & 2263 & 5071200 & & 40.3 & 0.6 \\
\hline \multicolumn{6}{|c|}{ Education status (years)* } \\
\hline$<6$ & 639 & 1156795 & & 9.5 & 0.5 \\
\hline $6-9$ & 453 & 1096297 & & 8.9 & 0.5 \\
\hline $10-12$ & 1849 & 5533191 & & 45.3 & 0.9 \\
\hline$>12$ & 1696 & 4432718 & & 36.3 & 0.9 \\
\hline \multicolumn{6}{|l|}{ Household income $†$} \\
\hline $1 Q$ & 569 & 1433998 & & 11.6 & 0.6 \\
\hline $2 Q$ & 1282 & 3483839 & & 28.1 & 1.0 \\
\hline $3 Q$ & 1419 & 3852908 & & 31.0 & 0.9 \\
\hline $4 Q$ & 1431 & 3636772 & & 29.3 & 1.0 \\
\hline \multicolumn{6}{|l|}{ Smoking status } \\
\hline Non-smoker & 2566 & 6233073 & & 49.5 & 0.8 \\
\hline Ex-smoker & 954 & 2464812 & & 19.6 & 0.7 \\
\hline Current smoker & 1241 & 3885881 & & 30.9 & 0.8 \\
\hline \multicolumn{6}{|c|}{ Heavy alcohol drinkingł } \\
\hline No & 3818 & 9731102 & & 79.0 & 0.7 \\
\hline Yes & 855 & 2593067 & & 21.0 & 0.7 \\
\hline \multicolumn{6}{|l|}{ Sleep time (h) } \\
\hline$\geq 6$ & 4131 & 10976795 & & 87.2 & 0.6 \\
\hline$<6$ & 630 & 1606971 & & 12.8 & 0.6 \\
\hline \multicolumn{6}{|c|}{ Perceived stress status $\S$} \\
\hline No & 3491 & 9076745 & & 74.2 & 0.8 \\
\hline Yes & 1154 & 3160474 & & 25.8 & 0.8 \\
\hline Cholesterol (mg/dL)ף & & & 186.5 & & 0.7 \\
\hline$<240$ & 3963 & 10666938 & & 89.6 & 0.5 \\
\hline$\geq 240$ & 578 & 1236374 & & 10.4 & 0.5 \\
\hline \multicolumn{6}{|l|}{ Atopy history } \\
\hline No & 4624 & 12123239 & & 96.3 & 0.4 \\
\hline Yes & 137 & 460527 & & 3.7 & 0.4 \\
\hline \multicolumn{6}{|l|}{ Anaemia } \\
\hline No & 4443 & 11843579 & & 94.1 & 0.4 \\
\hline Yes & 317 & 738388 & & 5.9 & 0.4 \\
\hline \multicolumn{6}{|l|}{ Dry eye (symptoms) } \\
\hline No & 4103 & 10952964 & & 87.0 & 0.7 \\
\hline Yes & 658 & 1630802 & & 13.0 & 0.7 \\
\hline Blood mercury levels & & & 3.7 & & 0.0 \\
\hline$<$ Median & 2379 & 6740444 & & 53.6 & 1.0 \\
\hline$\geq$ Median & 2382 & 5843322 & & 46.4 & 1.0 \\
\hline
\end{tabular}

Anaemia was defined as follows; for males with a haemoglobin level $<13 \mathrm{~g} / \mathrm{dL}$, pregnant females with a haemoglobin level $<11 \mathrm{~g} / \mathrm{dL}$, and non-pregnant females with a haemoglobin level $<12 \mathrm{~g} / \mathrm{dL}$.

The median cut-off levels that discriminate between subjects with 'low' and 'high' blood mercury levels were 4.26 and $2.89 \mu \mathrm{g} / \mathrm{L}$ for males and females, respectively.

*124 missing values.

t60 missing values.

$\ddagger 88$ missing values.

$\$ 116$ missing values.

१220 missing values.

soluble mucus (which is secreted by conjunctival goblet cells) mixed with fluid and proteins secreted by the lacrimal glands. ${ }^{22}{ }^{23}$ This hydrophilic gel moves over the membrane mucins (glycocalyx) on the superficial corneal and conjunctival epithelial cells and serves as a medium to refresh the tear components and clear 
Table 2 Comparison of the participants with and without dry eye symptoms in terms of general characteristics, socioeconomic status and blood mercury levels

\begin{tabular}{|c|c|c|c|c|c|c|c|}
\hline \multirow[b]{3}{*}{ Variable } & \multicolumn{6}{|l|}{ Dry eye symptom } & \multirow[b]{3}{*}{ p Value } \\
\hline & \multicolumn{3}{|l|}{ No } & \multicolumn{3}{|l|}{ Yes } & \\
\hline & Weighted Number & W \%* (mean) & SEt & Weighted Number & W \%* (mean) & SE & \\
\hline Age (years) & & (39.6) & $(0.2)$ & & (39.7) & $(0.6)$ & 0.861 \\
\hline$<30$ & 3311990 & 30.2 & 0.8 & 532742 & 32.7 & 2.3 & 0.242 \\
\hline 30-39 & 2408526 & 22.0 & 0.6 & 308558 & 18.9 & 1.8 & \\
\hline $40-49$ & 2535770 & 23.2 & 0.6 & 363243 & 22.3 & 2.1 & \\
\hline $50-59$ & 1799287 & 16.4 & 0.5 & 261054 & 16.0 & 1.7 & \\
\hline $60-69$ & 811313 & 7.4 & 0.3 & 140583 & 8.6 & 1.0 & \\
\hline$\geq 70$ & 86077 & 0.8 & 0.1 & 24621 & 1.5 & 0.4 & \\
\hline \multicolumn{8}{|l|}{ Gender } \\
\hline Men & 6853988 & 62.6 & 0.7 & 658578 & 40.4 & 2.4 & $<0.001$ \\
\hline Women & 4098976 & 37.4 & 0.7 & 972225 & 39.6 & 2.4 & \\
\hline \multicolumn{8}{|c|}{ Education status (years) $\dagger$} \\
\hline$<6$ & 949924 & 8.9 & 0.5 & 206871 & 12.9 & 1.6 & 0.062 \\
\hline $6-9$ & 969900 & 9.2 & 0.5 & 126397 & 7.9 & 1.3 & \\
\hline $10-12$ & 4844638 & 45.6 & 1.0 & 688553 & 43.0 & 2.6 & \\
\hline$>12$ & 3853297 & 36.3 & 1.0 & 579421 & 36.2 & 2.4 & \\
\hline \multicolumn{8}{|l|}{ Household income $\ddagger$} \\
\hline $1 Q$ & 1225036 & 11.4 & 0.6 & 208962 & 13.0 & 1.8 & 0.516 \\
\hline $2 Q$ & 3068394 & 28.4 & 1.0 & 415444 & 25.8 & 2.2 & \\
\hline $3 Q$ & 3368980 & 31.2 & 1.0 & 483928 & 30.1 & 2.3 & \\
\hline $4 \mathrm{Q}$ & 3136600 & 29.0 & 1.0 & 500172 & 31.1 & 2.5 & \\
\hline \multicolumn{8}{|l|}{ Smoking status } \\
\hline Non-smoker & 5249125 & 47.9 & 0.9 & 983948 & 60.3 & 2.2 & $<0.001$ \\
\hline Ex-smoker & 2181991 & 19.9 & 0.7 & 282821 & 17.3 & 1.8 & \\
\hline Current smoker & 3521847 & 32.2 & 0.9 & 364033 & 22.3 & 2.1 & \\
\hline \multicolumn{8}{|c|}{ Heavy alcohol drinking§ } \\
\hline No & 8344969 & 77.9 & 0.8 & 1386133 & 86.0 & 1.7 & $<0.001$ \\
\hline Yes & 2366814 & 22.1 & 0.8 & 226253 & 14.0 & 1.7 & \\
\hline \multicolumn{8}{|l|}{ Sleep time $(\mathrm{h})$} \\
\hline$\geq 6$ & 9587631 & 87.5 & 0.7 & 1389164 & 85.2 & 1.7 & 0.179 \\
\hline$<6$ & 1365333 & 12.5 & 0.7 & 241638 & 14.8 & 1.7 & \\
\hline \multicolumn{8}{|c|}{ Perceived stress status } \\
\hline No & 7998429 & 75.2 & 0.9 & 1078316 & 67.6 & 2.3 & 0.001 \\
\hline Yes & 2642978 & 24.8 & 0.9 & 517496 & 32.4 & 2.3 & \\
\hline Cholesterol** $\left.^{\star \star m g / d L}\right)$ & & (186.4) & $(0.7)$ & & $(187.4)$ & (1.9) & 0.607 \\
\hline$<240$ & 9274285 & 89.7 & 0.6 & 1392653 & 89.7 & 1.4 & 0.517 \\
\hline$\geq 240$ & 1060494 & 10.3 & 0.6 & 175880 & 10.3 & 1.4 & \\
\hline Anaemia & & & & & & & 0.823 \\
\hline No & 10322544 & 94.3 & 0.4 & 1521035 & 93.3 & 1.1 & \\
\hline Yes & 628621 & 5.7 & 0.4 & 109767 & 6.7 & 1.1 & \\
\hline \multicolumn{8}{|l|}{ Atopy history } \\
\hline No & 10552820 & 96.3 & 0.4 & 1570419 & 96.3 & 1.0 & 0.963 \\
\hline Yes & 400144 & 3.7 & 0.4 & 60383 & 3.7 & 1.0 & \\
\hline \multicolumn{8}{|l|}{ Blood mercury level } \\
\hline$<$ Median & 5953407 & 54.4 & 1.1 & 787037 & 48.3 & 2.5 & 0.021 \\
\hline$\geq$ Median & 4999557 & 45.7 & 1.1 & 843765 & 51.7 & 2.5 & \\
\hline 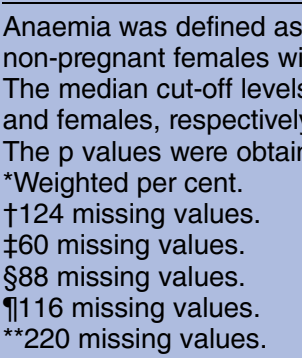 & $\begin{array}{l}\text { ollows; for males with a } \mathrm{h} \\
\text { a haemoglobin level }<12 \\
\text { hat discriminated betwee } \\
\text { d by comparing the parti }\end{array}$ & $\begin{array}{l}\text { gemoglobin level< } \\
\mathrm{g} / \mathrm{dL} \text {. } \\
\text { n participants with } \\
\text { ipants with and wi }\end{array}$ & $\begin{array}{l}3 \mathrm{~g} / \mathrm{dL} \text {, } \\
\text { low' anc } \\
\text { hout dry }\end{array}$ & $\begin{array}{l}\text { regnant females with a } \\
\text { 'high' blood mercury lev } \\
\text { eye symptoms using }\end{array}$ & $\begin{array}{l}\text { aemoglobin level } \\
\text {-Scott } \chi^{2} \text { analysis }\end{array}$ & $\begin{array}{l}11 \mathrm{~g} / \mathrm{dL} \\
89 \mu \mathrm{g} / \mathrm{L}\end{array}$ & $\begin{array}{l}\text { and } \\
\text { for males }\end{array}$ \\
\hline
\end{tabular}


Table 3 Logistic regression analysis of the association between dry eye symptom prevalence and demographic and clinical variables before and after adjustment for confounding factors

\begin{tabular}{|c|c|c|c|c|}
\hline & \multicolumn{2}{|l|}{ Crude } & \multicolumn{2}{|l|}{ Model 1} \\
\hline & $\overline{\text { OR }}$ & $95 \% \mathrm{Cl}$ & $\overline{\text { OR }}$ & $95 \% \mathrm{Cl}$ \\
\hline $\begin{array}{l}\text { Age (years) (continuous) } \\
<30\end{array}$ & $\begin{array}{l}1.001 \\
\text { reference }\end{array}$ & (0.993 to 1.008$)$ & $\begin{array}{l}0.964 \\
\text { reference }\end{array}$ & (0.874 to 1.064$)$ \\
\hline $30-39$ & 0.831 & (0.617 to 1.119$)$ & 0.798 & (0.589 to 1.079 ) \\
\hline $40-49$ & 0.876 & (0.654 to 1.173 ) & 0.809 & (0.588 to 1.113 ) \\
\hline $50-59$ & 0.904 & (0.649 to 1.260$)$ & 0.811 & (0.547 to 1.201 ) \\
\hline $60-69$ & 1.092 & (0.799 to 1.493$)$ & 0.923 & (0.608 to 1.402$)$ \\
\hline$\geq 70$ & 2.032 & (1.155 to 3.576$)$ & 1.570 & (0.767 to 3.210$)$ \\
\hline \multicolumn{5}{|l|}{ Gender } \\
\hline Men & reference & & reference & \\
\hline Women & 2.502 & (2.005 to 3.124$)$ & 2.378 & (1.676 to 3.372$)$ \\
\hline \multicolumn{5}{|l|}{ Education status (years) } \\
\hline$<6$ & reference & & reference & \\
\hline $6-9$ & 0.564 & (0.361 to 0.881$)$ & 0.720 & (0.415 to 1.169$)$ \\
\hline $10-12$ & 0.645 & (0.463 to 0.900$)$ & 0.824 & (0.538 to 1.263 ) \\
\hline$>12$ & 0.629 & (0.489 to 0.942$)$ & 0.862 & (0.554 to 1.340$)$ \\
\hline \multicolumn{5}{|l|}{ Household income } \\
\hline $1 Q$ & reference & & reference & \\
\hline $2 Q$ & 0.695 & (0.483 to 1.002$)$ & 0.800 & (0.530 to 1.207$)$ \\
\hline $3 \mathrm{Q}$ & 0.733 & $(0.507$ to 1.060$)$ & 0.879 & (0.577 to 1.337$)$ \\
\hline $4 Q$ & 0.841 & (0.579 to 1.223 ) & 0.956 & (0.625 to 1.463$)$ \\
\hline \multicolumn{5}{|l|}{ Smoking status } \\
\hline Non-smoker & reference & & reference & \\
\hline Ex-smoker & 0.698 & (0.532 to 0.915$)$ & 1.124 & (0.797 to 1.585$)$ \\
\hline Current smoker & 0.527 & (0.400 to 0.694$)$ & 0.900 & (0.622 to 1.304$)$ \\
\hline \multicolumn{5}{|l|}{ Heavy alcohol drinking } \\
\hline No & reference & & reference & \\
\hline Yes & 0.564 & (0.414 to 0.768$)$ & 0.945 & (0.643 to 1.391$)$ \\
\hline \multicolumn{5}{|l|}{ Sleep time (h) } \\
\hline$\geq 6$ & reference & & reference & \\
\hline$<6$ & 1.338 & $(0.978$ to 1.831$)$ & 1.141 & (0.815 to 1.597$)$ \\
\hline \multicolumn{5}{|l|}{ Perceived stress status } \\
\hline No & reference & & reference & \\
\hline Yes & 1.357 & (1.071 to 1.719$)$ & 1.330 & (1.046 to 1.692$)$ \\
\hline \multicolumn{5}{|l|}{ Cholesterol (mg/dL) } \\
\hline$<240$ & reference & & reference & \\
\hline$\geq 240$ & 1.129 & (0.836 to 1.524$)$ & 1.055 & (0.768 to 1.450$)$ \\
\hline \multicolumn{5}{|l|}{ Atopy history } \\
\hline No & reference & & reference & \\
\hline Yes & 0.848 & (0.457 to 1.574$)$ & 0.777 & (0.415 to 1.453 ) \\
\hline \multicolumn{5}{|l|}{ Anaemia } \\
\hline No & reference & & reference & \\
\hline Yes & 1.215 & (0.830 to 1.778$)$ & 0.803 & ( 0.430 to 1.499$)$ \\
\hline \multicolumn{5}{|l|}{ Blood mercury levels } \\
\hline$<$ Median & reference & & reference & \\
\hline$\geq$ Median & 1.303 & (1.056 to 1.607$)$ & 1.324 & (1.059 to 1.655$)$ \\
\hline
\end{tabular}

Italics indicate that the variable was inserted in the survey logistic regression as a continuous variable.

The data from Model 1 are after adjusting for age, gender, education, total household income, smoking status, heavy alcohol status, sleep time, perceived stress status, cholesterol levels and atopy history.

Anaemia was defined as follows; for males with a haemoglobin level $<13 \mathrm{~g} / \mathrm{dL}$, pregnant females with a haemoglobin level $<11 \mathrm{~g} / \mathrm{dL}$, and non-pregnant females with a haemoglobin level $<12 \mathrm{~g} / \mathrm{dL}$.

The median cut-off levels that discriminated between participants with 'low' and 'high' blood mercury levels were 4.26 and $2.89 \mu \mathrm{g} / \mathrm{L}$ for males and females, respectively.

debris. In dry eye syndrome, the mucins are altered ${ }^{24}$ and inflammatory/immune cells on the ocular surface (particularly $\mathrm{CD} 4+$ and $\mathrm{CD} 17+\mathrm{T}$ cells) are activated or recruited to the conjunctival epithelium. ${ }^{25} 26$ The inflammation on ocular surface promotes the corneal epithelial disease in dry eye syndrome and evokes dry eye symptoms such as persistent dryness or sense of eye irritation. The possibility that mercury induces dry eye 
Table 4 Multiple survey logistic regression analysis of the association between dry eye symptom prevalence and blood mercury levels using median $\pm 10 \%$ range (45th, 50 th and 55th percentile) mercury values as the cut-off

\begin{tabular}{lll}
\hline & \multicolumn{2}{l}{ Dry eye symptom } \\
\cline { 2 - 3 } Cut-off mercury level & OR & $\mathbf{9 5 \%} \mathbf{C l}$ \\
\hline Median-10\% range & 1.321 & $(1.055$ to 1.653$)$ \\
Median & 1.324 & $(1.059$ to 1.655$)$ \\
Median+10\% range & 1.329 & $(1.061$ to 1.664$)$ \\
\hline
\end{tabular}

The median-10\% range cut-off levels that discriminated between participants with 'low' and 'high' blood mercury levels were 3.99 and $2.72 \mu \mathrm{g} / \mathrm{L}$ for males and females, respectively.

The median cut-off levels that discriminated between participants with 'low' and 'high' blood mercury levels were 4.26 and $2.89 \mu \mathrm{g} / \mathrm{L}$ for males and females, respectively.

The median $+10 \%$ range cut-off levels that discriminated between participants with 'low' and 'high' blood mercury levels were 4.61 and $3.10 \mu \mathrm{g} / \mathrm{L}$ for males and females, respectively.

syndrome by promoting ocular surface inflammation is supported by a study on 12 rabbits that showed that metallic mercury in the conjunctiva increases the numbers of conjunctival lymphocytes and macrophages; it also associates with increased amounts of altered mucus. ${ }^{10} \mathrm{~A}$ previous report demonstrated that the subcutaneous injection of mercury can develop an autoimmune syndrome with infiltration of mononuclear cells into the oral mucosa, salivary and lacrimal glands. ${ }^{27}$ We speculate that mercury induced autoimmunity in the lacrimal glands might reduce tear production and induce conjunctival inflammation, resulting in dry eye syndrome.

The second possible mechanism that explains the relationship between mercury and dry eye syndrome is that mercury depletes the conjunctivae of antioxidant proteins such as metallothioneins. These cysteine-rich low-molecular-weight proteins help to prevent tissue inflammation. ${ }^{28}$ They are thought to bind heavy metals such as mercury in the blood, thereby removing heavy metals that can induce oxidative stress. ${ }^{5} 28{ }^{29}$ We speculate that a persistent, albeit low level, exposure of the conjunctiva to mercury, such as in our Korean population, may reduce the availability of free metallothioneins in the lacrimal glands and conjunctiva. This, in turn, may increase the susceptibility of the ocular surface to inflammation and dry eye symptoms. Experimental studies that test these potential mechanisms by which mercury may promote dry eye syndrome are warranted.

There seems to be an association between smoking status and dry eye symptoms. ${ }^{30} 31$ However, in this study, smoking status is not statistically significant. The gender difference in smoking status may be the possible reason why the discrepancy remains. In tables 2 and 3, females were likely to have a higher association with dry eye symptoms. According to previous research on smoking status by gender, ${ }^{32}$ the smoking rate in Korean females was much lower than that in Korean males. We speculate that different smoking status by gender in this population might cause these results.
This study has a few limitations. First, its cross-sectional design means that the association observed in this study cannot be interpreted as a cause-and-effect relationship. A large-scale population-based longitudinal study that can assess causality is warranted. Second, we did not adjust for other factors that could confound the relationship between mercury and dry eye symptoms, including the use of contact lenses or systemic drugs (including traditional oriental medicines). Third, we did not examine the effect of occupational exposure because KNHANES does not ask about occupation. Fourth, we used the median blood mercury concentration of our population as the cut-off level to distinguish participants with 'low' and 'high' blood mercury levels. Whether this is the best approach or not may be debatable. However, the sensitivity tests shown in table 4 indicated that the optimal cut-off level is the median $\pm 10 \%$ (ie, between the 45th and 55th centiles) as the ORs and $p$ values for the relationship between dry eye symptoms and these alternative cut-offs were similar to those when the 50th centile was employed. Fifth, we could not analyse the relationship between physician-diagnosed dry eye and blood mercury levels. However, physician-diagnosed dry eye is not a good index for health outcomes for several reasons. First, mercury has a relatively short half-life in the blood due to its rapid distribution to other tissues while its halflife in the body is about 2 months. ${ }^{53}$ We hypothesised, therefore, that questionnaire-determined dry eye symptoms would mirror recent exposure to mercury better than physician-diagnosed dry eye syndrome, which could reflect earlier exposure to mercury that has long ago left the circulation a long time ago. Second, the KNHANES design did not include a direct physical examination to define dry eye, namely using a slit-lamp. This is because the survey was large and its main purpose was to evaluate the prevalence of and risk factors for dry eye. If dry eye syndrome would be diagnosed according to standard guidelines, the association between mercury and dry eye symptoms observed in this study might be altered. To reduce this information bias, further evaluation with an objective tool for diagnosing dry eye syndrome should be incorporated into a nationwide survey in Korea.

This study also had several strengths. First, it was a large-scale study that was based on a nationally representative Korean population. Second, potential confounders reported in the literature were excluded or the analyses were adjusted for them.

\section{CONCLUSIONS}

In conclusion, recent environmental exposure to mercury was associated with the presence of dry eye symptoms. To elucidate a causal relationship between mercury exposure and dry eye syndrome, further longitudinal and experimental studies are needed. Our observations also suggest that to reduce the prevalence of dry eye syndrome, public health measures that control the dietary and polluted air sources of mercury are needed. 
Acknowledgements The authors thank the Epidemiological Survey Committee of the Korean Ophthalmologic Society for conducting the KNHANES examinations and supplying the data for this study. The quality of language in this manuscript was improved with the assistance of the professional editing agency Bioedit.

Contributors S-HC drafted the manuscript and contributed to the data interpretation and statistical analyses. J-PM contributed to the study design, statistical analyses and interpretation of data.

Funding This work was supported by a grant from the Korea Health Technology R\&D Project, Ministry of Health \& Welfare, Republic of Korea (HI14C1607).

Competing interests None declared.

Patient consent Obtained

Ethics approval The use of publicly released data and the study protocol were approved by the Institutional Review Board of Seoul St. Mary's Hospital Catholic University of Korea (approval ID: KC14EISI0877).

Provenance and peer review Not commissioned; externally peer reviewed.

Data sharing statement No additional data are available.

Open Access This is an Open Access article distributed in accordance with the Creative Commons Attribution Non Commercial (CC BY-NC 4.0) license, which permits others to distribute, remix, adapt, build upon this work noncommercially, and license their derivative works on different terms, provided the original work is properly cited and the use is non-commercial. See: http:// creativecommons.org/licenses/by-nc/4.0/

\section{REFERENCES}

1. Chia EM, Mitchell P, Rochtchina E, et al. Prevalence and associations of dry eye syndrome in an older population: the Blue Mountains Eye Study. Clin Experiment Ophthalmol 2003;31: 229-32.

2. McCarty CA, Bansal AK, Livingston PM, et al. The epidemiology of dry eye in Melbourne, Australia. Ophthalmology 1998;105:1114-19.

3. The committee of the International Dry Eye WorkShop. The definition and classification of dry eye disease: report of the Definition and Classification Subcommittee of the International Dry Eye WorkShop (2007). Ocul Surf 2007:5:75-92.

4. The committee of the International Dry Eye WorkShop. The epidemiology of dry eye disease: report of the Epidemiology Subcommittee of the International Dry Eye WorkShop (2007). Ocul Surf 2007;5:93-107.

5. Bernhoft RA. Mercury toxicity and treatment: a review of the literature. J Environ Public Health 2012;2012:460508.

6. Warfvinge K, Bruun A. Mercury distribution in the squirrel monkey retina after in Utero exposure to mercury vapor. Environ Res 2000;83:102-9

7. Bridges CC, Battle JR, Zalups RK. Transport of thiol-conjugates of inorganic mercury in human retinal pigment epithelial cells. Toxicol Appl Pharmacol 2007;221:251-60.

8. Tanan CL, Ventura DF, de Souza JM, et al. Effects of mercury intoxication on the response of horizontal cells of the retina of thraira fish (Hoplias malabaricus). Braz J Med Biol Res 2006;39:987-95.

9. Beuter A, Edwards R. Effect of chronic exposure to methylmercury on eye movements in Cree subjects. Int Arch Occup Environ Health 2004;77:97-107.

10. Kulczycka B. Resorption of metallic mercury by the conjunctiva. Nature 1965;206:943.
11. Stevenson W, Chauhan SK, Dana R. Dry eye disease: an immunemediated ocular surface disorder. Arch Ophthalmol 2012;130:90-100

12. Jeong $\mathrm{H}$, Hong $\mathrm{S}$, Heo $\mathrm{Y}$, et al. Vitamin $\mathrm{D}$ status and associated occupational factors in Korean wage workers: data from the 5th Korea national health and nutrition examination survey (KNHANES 2010-2012). Ann Occup Environ Med 2014;26:28.

13. Korea Center for Disease Control and Prevention. Korea National Health and Nutrition Examination Survey V. 2010-2012. http://knhanes.cdc.go.kr/ (accessed 1 Dec 2014).

14. Karagas MR, Choi AL, Oken E, et al. Evidence on the human health effects of low-level methylmercury exposure. Environ Health Perspect 2012;120:799-806.

15. Bakir F, Damluji SF, Amin-Zaki L, et al. Methylmercury poisoning in Iraq. Science 1973;181:230-41.

16. Skerfving SB, Copplestone JF. Poisoning caused by the consumption of organomercury-dressed seed in Iraq. Bull World Health Organ 1976;54:101-12.

17. Baughman TA. Elemental mercury spills. Environ Health Perspect 2006;114:147-52.

18. Gabal MS, Raslan OA. Ocular disorders among workers exposed to mercury. J Egypt Public Health Assoc 1995;70:1-14.

19. Kim NS, Lee BK. Blood total mercury and fish consumption in the Korean general population in KNHANES III, 2005. Sci Total Environ 2010;408:4841-7

20. Korea Ministry of Food and Drug Safety. Library of Toxic Substances. 2000. http://foodnara.go.kr/foodnara/board-list.do? boardld=series\&mid=S07_05_03 (accessed 27 Aug 2014).

21. $\mathrm{Ng} \mathrm{TH}$, Mossey JM, Lee BK. Total blood mercury levels and depression among adults in the United States: National Health and Nutrition Examination Survey 2005-2008. PLoS ONE 2013;8:e79339.

22. Dursun D, Monroy D, Knighton R, et al. The effects of experimental tear film removal on corneal surface regularity and barrier function. Ophthalmology 2000;107:1754-60.

23. Nichols BA, Chiappino ML, Dawson CR. Demonstration of the mucous layer of the tear film by electron microscopy. Invest Ophthalmol Vis Sci 1985;26:464-73.

24. Spurr-Michaud S, Argueso P, Gipson I. Assay of mucins in human tear fluid. Exp Eye Res 2007;84:939-50.

25. De Paiva CS, Chotikavanich S, Pangelinan SB, et al. IL-17 disrupts corneal barrier following desiccating stress. Mucosal Immunol 2009;2:243-53.

26. De Paiva CS, Villarreal AL, Corrales RM, et al. Dry eye-induced conjunctival epithelial squamous metaplasia is modulated by interferon-gamma. Invest Ophthalmol Vis Sci 2007;48:2553-60.

27. Warfvinge G, Warfvinge K, Larsson A. Histochemical visualization of mercury in the oral mucosa, salivary and lacrimal glands of $\mathrm{BN}$ rats with $\mathrm{HgCl} 2$-induced autoimmunity. Exp Toxicol Pathol 1994;46:329-34.

28. Kumari MV, Hiramatsu M, Ebadi M. Free radical scavenging actions of metallothionein isoforms I and II. Free Radic Res 1998;29:93-101.

29. Sinaie M, Bastami KD, Ghorbanpour M, et al. Metallothionein biosynthesis as a detoxification mechanism in mercury exposure in fish, spotted scat (Scatophagus argus). Fish Physiol Biochem 2010;36:1235-42

30. Moss SE, Klein R, Klein BE. Prevalence of and risk factors for dry eye syndrome. Arch Ophthalmol 2000;118:1264-8.

31. Uchino $\mathrm{M}$, Nishiwaki $\mathrm{Y}$, Michikawa $\mathrm{T}$, et al. Prevalence and risk factors of dry eye disease in Japan: Koumi study. Ophthalmology 2011;118:2361-7.

32. Jung-Choi $\mathrm{KH}$, Khang $\mathrm{YH}$, Cho HJ. Hidden female smokers in Asia: a comparison of self-reported with cotinine-verified smoking prevalence rates in representative national data from an Asian population. Tob Control 2012;21:536-42.

33. Mela M, Cambier S, Mesmer-Dudons N, et al. Methylmercury localization in Danio rerio retina after trophic and subchronic exposure: a basis for neurotoxicology. Neurotoxicology 2010;31:448-53. 